\title{
An Evaluation of Furniture Making Methods for Yachts
}

\author{
Emre Ergul $^{1}$, Andrea Ratti ${ }^{2}$, Sebastiano Ercoli ${ }^{2}$, Arianna Bionda ${ }^{2}$ \\ ${ }^{1}$ Department of Interior Architecture and Environmental Design, Izmir University of Economics, Izmir, Turkey \\ ${ }^{2}$ Design Department, Politecnico di Milano, Milano, Italy
}

\section{Email address:}

emre.ergul@ieu.edu.tr(E.Ergul), andrea.ratti@polimi.it (A. Ratti), sebastiano.ercoli@gmail.com (S. Ercoli), arianna.bionda@polimi.it (A. Bionda)

\section{To cite this article:}

Emre Ergul, Andrea Ratti, Sebastiano Ercoli, Arianna Bionda. An Evaluation of Furniture Making Methods for Yachts. American Journal of Mechanical and Industrial Engineering. Vol. 2, No. 6, 2017, pp. 205-211. doi: 10.11648/j.ajmie.20170206.11

Received: July 12, 2017; Accepted: July 28, 2017; Published: January 8, 2018

\begin{abstract}
There are mainly three different methods of furniture making for yachts as on-site method, mock-up method and computerized method. On-site method is the oldest and traditional way which has been developed by old talented wooden boat builders. In fact, the method is still alive in many small boatyards where the artisans apply the techniques learned by their masters. Mock-up method separates the construction process into two: boat building and furniture making. Hull, bulkheads, engines installation, mechanical and electrical infrastructure, all are made by a boatyard and furnitures are made by a subcontractor, which indicates the furniture making is a specialization. Computerized method is the advanced way, developed in the last decade. All furnitures are drawn phase by phase by the sub-contractor's design team in detail and after the drawings are approved, production starts. Time planning, a clear definition of work sharing and responsibility are the key issues of this contemporary system. Within the scope of this study, all methods are explained widely. This study depends on an empirical research realized in furniture making companies and boatyards. Knowledge gained by both unstructured observations of making processes and interviews with responsible persons. Data is evaluated by qualitative methods. It is an attempt to understand the case and in line with its complementary understanding approach, a deductions set is given together with the observations and interviews in each making method. Then, four variables are determined to evaluate the furniture making methods: a. boat size and purpose of use, b. equipment and organizational capacity of furniture company, c. making time, and d. tolerance for decision changes. As a conclusion, three different methods of furniture makingdemonstrate three different work scales, but not the quality of end product.
\end{abstract}

Keywords: Boat Furniture, Yacht Design, On-Site Furniture Making, Mock-up System, Computer Controlled Furniture Making

\section{Introduction}

Furniture making for yachts needs aspecialand different understanding of and approach to the case than making furniture for the spaces on the land. A yacht is a complex product and ergonomics have a key role in the design and construction process. Sea conditions do not allow to place any unfixed element into the boat, otherwise it moves on a wavy sea journey, may fall down and break something or moreover, may injure somebody. Similarly, sharp edges are dangerous when somebody is unbalanced, so the corners are recommended to be round and coated with a soft material to avoid from harmful accidents. There should be grab rails or poststo hold, for the passenger safety not only in a sailing boat, but also in a motor boat especially if she is navigated on open seas. Since the furniture of a boat includes partition walls, ceiling structure and flooring as well as seating elements, tables, beds, cupboards, galley cabinets and so on, it is a system, of which the elements are connected to each other tightly. Engines of a motor boat create a vibration which makes a force on the joints of this system. Likewise, the stress on the hull of a sailing boat in a regatta causes the same. Upwind navigation in a stormy weather condition moves the bow up and down, thus the furniture system is impacted. These conditions require special joints, absorbtion and lock systems to be developed. According to the inclination angle of the boat, accessories and objects on a desk, counter and shelves slip and fall down if no spesific 
solution is considered to keep them fixed. The structure of a berth is not simply a single wooden panel construction. Instead, it is a two panels structure with short wooden posts in, like a partition wall.

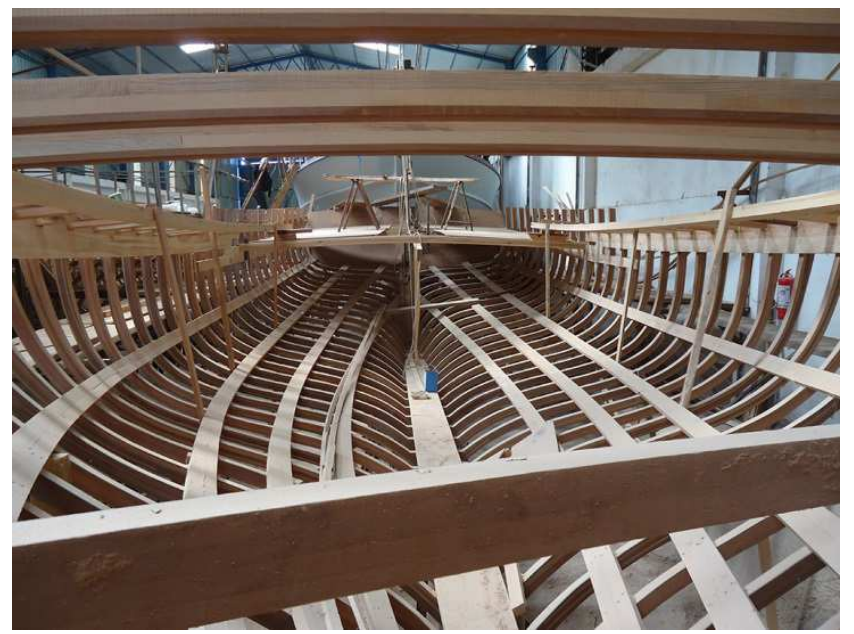

Figure 1. Keel, stringers and stations of a wooden boat structure.

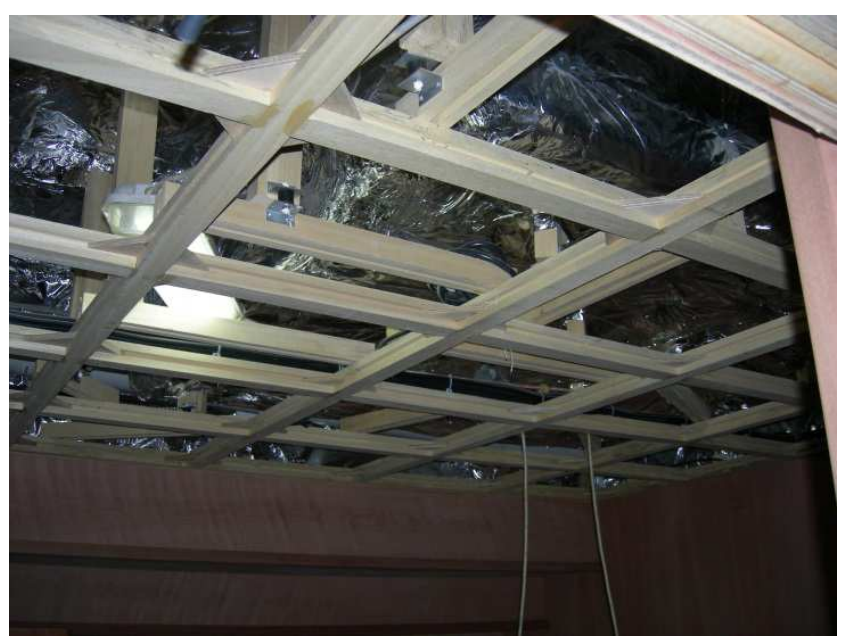

Figure 2. Ceiling structure is a grid system of wooden elements.

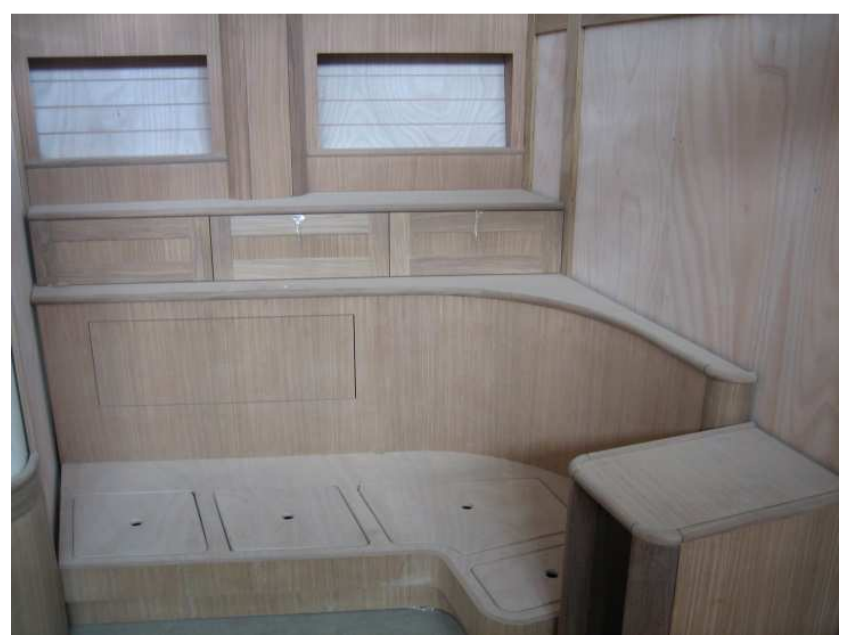

Figure 3. Panels are fixed on a stepped wooden structure at the hull side.

Walls and ceilings are not continous surfaces, they are made of modules mounted on a grid structure and the infrastructure of the boat behind should always be accessible. Flooring is the same, panels are opened for accessing to the bilge volume. Every volume, even a very small one should be used efficiently to store something in. Clothes, shoes, food and drinks for a long journey, galley accessories and hand tools, substitutes like fuel, ropes and sails, needed equipment like maps and flags, allshould be stored and no volume should be left over. Material selection is another critical issue in boat furniture making, all should be waterproof, fire resistant or retardant and when it burns, it should not exhale toxic gas. In this sense, solid wood and marine plywood are acceptable to a certain extend, but mdf (medium density fiberboard) and osb (oriented strand board) are not. Finally, the shape of the hull in the lower deck is curvilinear, this is compelling for the craftsmen more particularly in the cabin at the bow. A stepped furniture with a two directional inclined backing is made which should perfectly fits to the hull shape. This means a very skillful craftsmenship, a precise and dedicated work is required. In short, furniture making for the boats is a very special case. At this point, it should be stated that the focus of this study is custom tailored boat construction, not the mass production boats. It is known that custom tailored boats, also called as pleasure yachts, aregenerally 30 to 80 meters long boatsconstructed by the demand of a user, hence they are user centered anddesigned for the needs and lifestyle of the user or users.

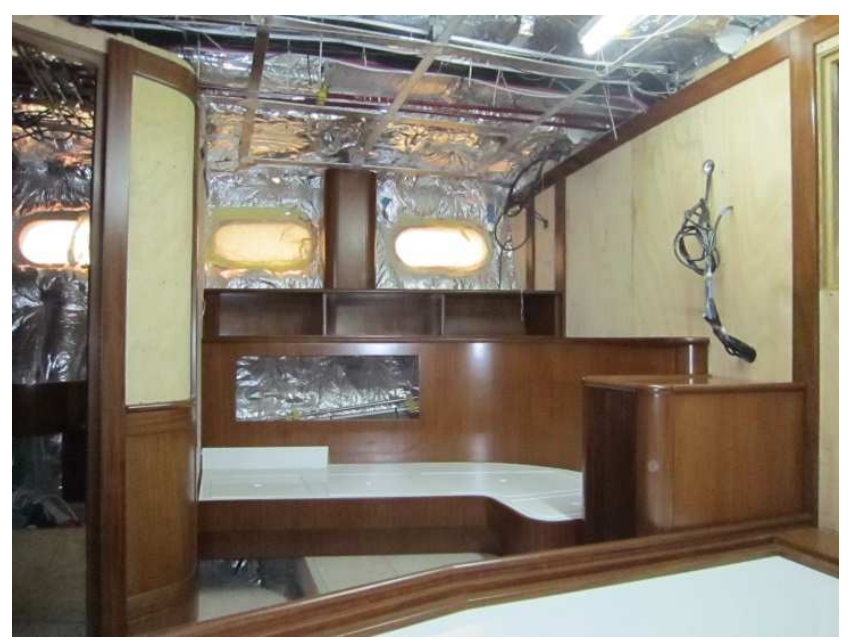

Figure 4. Lac applied wooden modules are mounted on walls.

\section{Method of the Study}

This study depends on an empirical research realized in furniture making companies and boatyards. Knowledge gained by both unstructured observations of making processes and interviews with responsible persons. Data is evaluated by qualitative methods. It is an attempt to understand the case and in line with its complementary understanding approach, a deductions set is given together with the observations and interviews in each making method. Then, four variables are determined to evaluate the furniture making methods: a. boat size and purpose of use, b. equipment and organizational 
capacity of furniture company, c. making time, and d. tolerance for decision changes. There are mainly three different methods of furniture making for yachts as on-site method, mock-up method and computerized method. On-site method is the oldest and traditional way which has been developed by old talented wooden boat builders. In fact, the method is still alive in many small boatyards where the artisans apply the techniques learned by their masters. Mock-up method separates the construction process into two: boat building and furniture making. Hull, bulkheads, engines installation, mechanical and electrical infrastructure, all are made by a boatyard and furnitures are made by a sub-contractor, which indicates the furniture making is a specialization. Computerized method is the advanced way, developed in the last decade. All furnitures are drawn phase by phase by the sub-contractor's design team in detail and after the drawings are approved, production starts. Time planning, a clear definition of work sharing and responsibility are the key issues of this contemporary system. Within the scope of this study, all methods are explained widely.

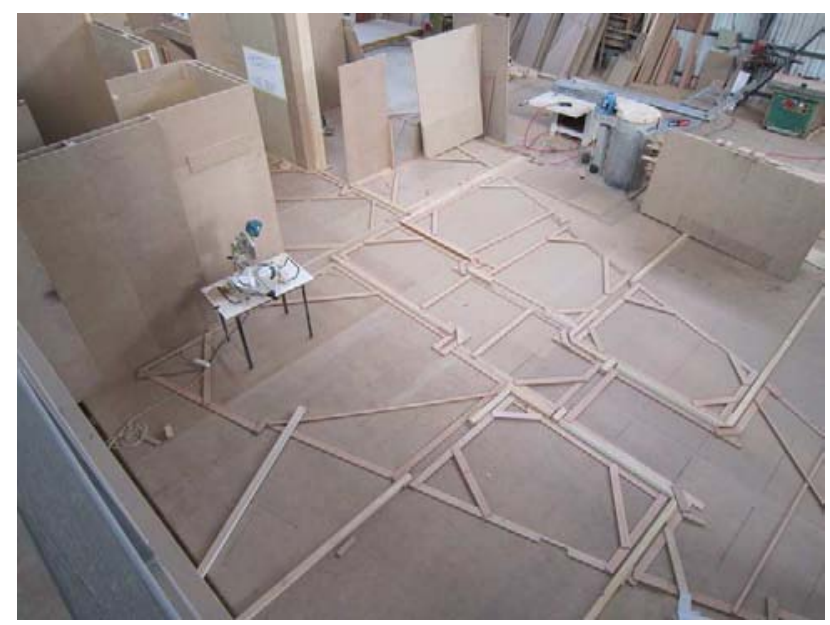

Figure 5. Plan layout of partition walls are made by wooden guides.

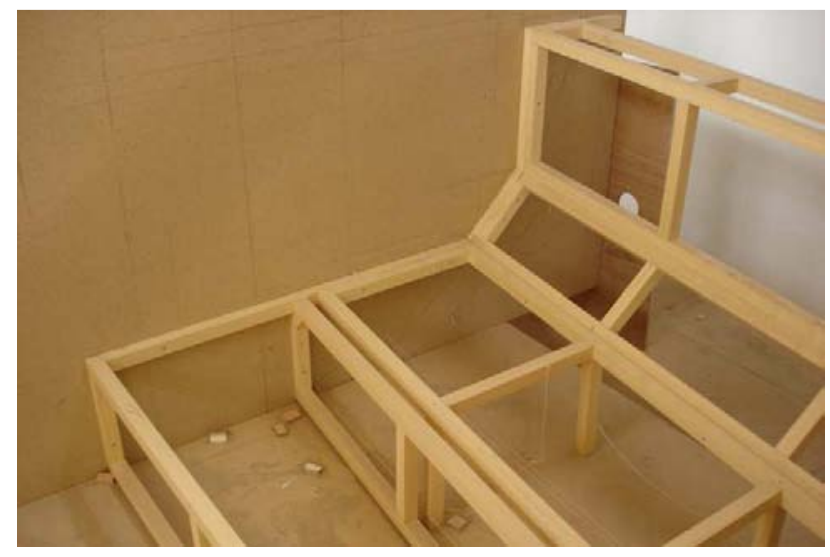

Figure 6. Wooden framing of a berth is placed with $40 \mathrm{~cm}$. distances.

\section{Furniture Making Methods}

\subsection{On-Site Method}

Since the on-site method is an integral part of a boat structure and both of them are made by the same craftsmen team in many cases, describing the method will start with the boat herself. Main materialissolid wood and marine plywood today. Craftsmen begin with making the keel with laminated plywood strips joined to each other all along the centerline, then go on with placing stations and stringers in order to complete the hull structure. Later, beams are connected at every station to span the distance of width "Figure 1". Shape and size of the elements are decided by the master, depending on his experience and creativity gained in many years, obviously it is according to the engineering project nowadays [1]. Planking with almost $10 \mathrm{~mm}$. thickness wooden strips is a 3 or 5 layers application to build the hull surface. Strips of a layer follows a crossing way than the previous one and each was nailed in the past but is stapled with $U$ shaped fiber pieces today [2]. After the planking is finished, flooring starts. It is a grid composition of wooden beams on which plywood panels are screwed. Some of the panels are openable to access the bilge volume where the tanks, pipes and propulsion systems are installed. Then the structure of partition walls is made by using $6 \times 6 \mathrm{~cm}$. sectioned wooden elements in vertical and horizontal positioning with a $40 \mathrm{~cm}$. distances inbetween. Cells of this structure are stiffened with triangle shaped corner supports. So the cabins layout is roughly finalised. Both wall sides are cladded with $10 \mathrm{~mm}$. thickness plywood panels as base layers. Second layer is another plywood panels layer mounting in modules as a finishing layer which might be of leather or any marine textile coated, wood veneered or lac applied. Ceiling structure has the same grid system with partition walls, but the elements are smaller sized [3]. It is not screwed to the beams of boat structure, instead, connected to it by special joints madeof two L shaped metal brace clamps with a rubber piece inbetween "Figure 2". This is for absorbing the vibration or stress on the boat structure. No base material is applied, only one layer of plywood in modules which are clipped to the ceiling structure, means some of them can be opened to access the electricity systems into the ceiling volume.

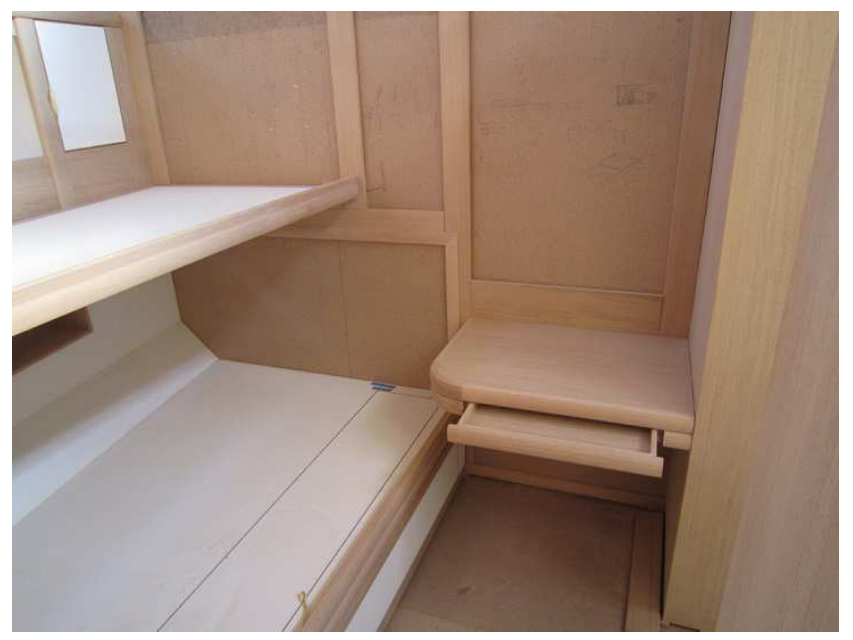

Figure 7. Furniture edges should be round for the passenger safety. 


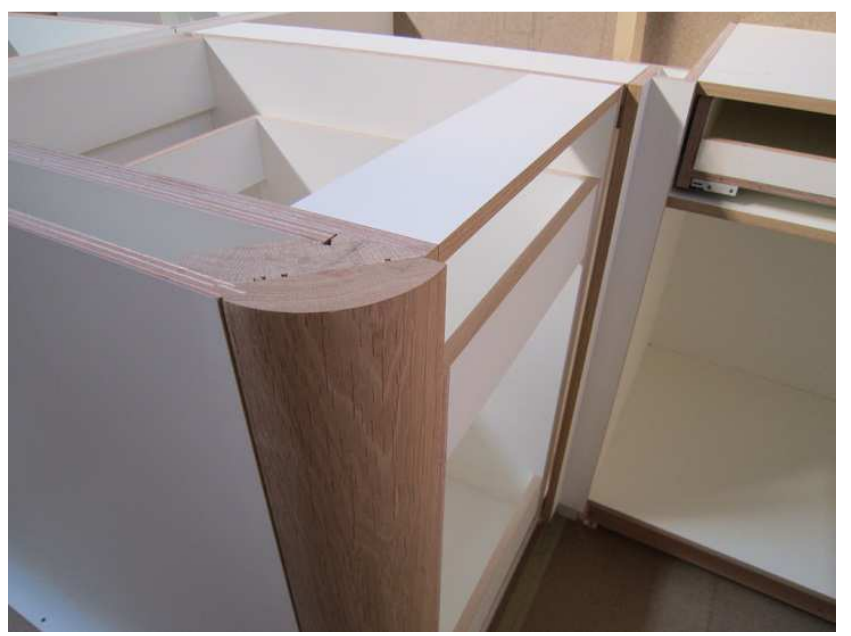

Figure 8. The round edge of a cabinet with two panels and wooden posts.

Finishing material on the floor might be marine carpet or teak planks epoxy resin glued as a common application. On the other hand, making cupboards, cabinets or berths on the port or starboard side needs a special attention and a precise craftsmenship [4]. Because the surfaces on both sides are curvilinear from top to down and bow to stern and the volumes should be used efficiently, so a continous straight vertical surface can not be made. Otherwise, it means that too much space is unused or leftover. Vertical and horizontal elements of a furniture such as the side of a berth or a countertop of a cabinet should be mounted on a wooden structure at its behind. Hence, a stepped structure from the floor level to up is constructed, then wooden panels are fixed onto them "Figure 3". This makes the problem more complex and entails a detaileddesign solution which can only be developed on-site. Especially the details of a cabin at the bow on the lower deck can not be drawn simply in a design office before the construction, rather, shop drawings are required. Concisely, in this method of making, as usual the craftsmen make a decision on-site with the guidance of a surveyor, measure the distance, cut the piece and fit it to its place. If the piece does not fit, then it is rasped until it is properly done. A high level of craftsmenship quality and a dedicated work play a key role in the making process [5]. Craftsmen team set the machines such as the sawing machine, thickness planer and milling machine nearby the boat, prepare the elements of furniture and then get on the board for the first installation. Small operations are made by hand tools inside the boat, but the cutting is at the outside to avoid from dusting. They get on and off the board many times to measure a distance and to plane any piece. Measuring and marking are made by using conventional rulers and the correction is by the hand-eye coordination of the master. After then, elements to be varnished or polished are demounted and sent to another workshop or slight possibility to an isolated space in the boatyard. Likewise, elements to be lac or paint applied or leather or textile coated are demounted as well "Figure 4". Once the installation of all furniture elements are completed, fixtures like knobs, handles and locks are assembled. The result is expected to be a handcrafted artisan work but naturally it takes longer time than the other methods.

\subsection{Mock-up Method}

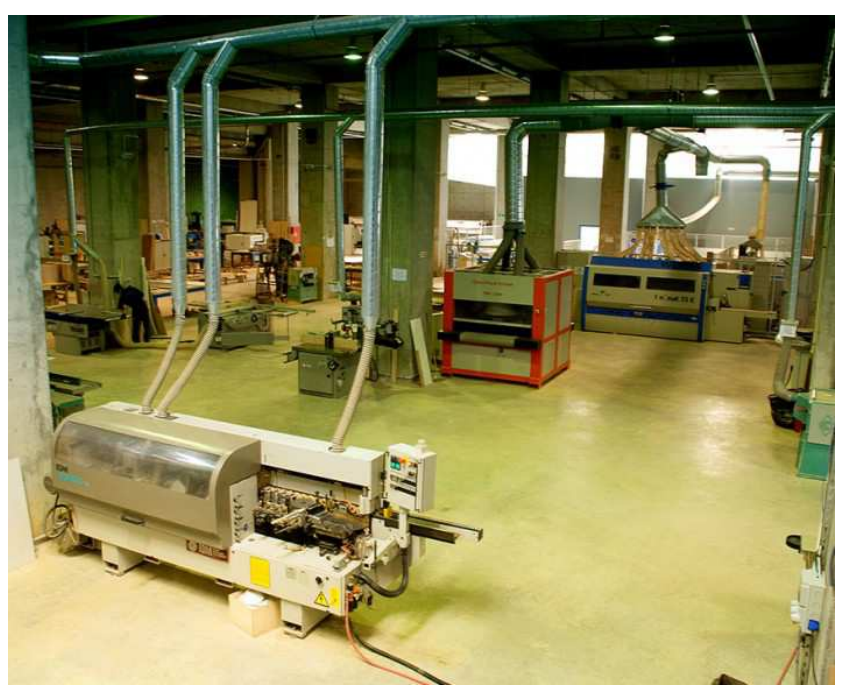

Figure 9. Machines and manufacturing units for the bulk production.

In this method, boatyard and the furniture company as a sub-contractor are two different bodies totally separated from each other. Boatyard builds the hull, bulkheads and superstructure, installs the infrastructure and propulsion systems whereas the sub-contractor is the responsible of producing furnitures with its own machines and craftsmen team in its own workshop. Therefore, a detailed project, time planning and a clear definition of the work are complementary documents of the contract [6]. Before starting to make the furnitures, mock-up of the boat should be constructed first, so it starts with getting the printouts of related stations. If she is a motor boat, the mock-up of lower deck is in two parts, the first starts from the main bulkhead to the engine room and the second is from the stern side of engine room to the stern. If she is a sailing boat, it covers the whole lower deck from the bow to stern. Main deck is the same, the mock-up is a single whole, it is not constructed in separate parts unless the boat is longer than the workshop. It means that this method requires a considerably big space than the on-site method. First, the floor is made of wooden framing and mdf sheets including the level differences. Then, each station axis of the project is drawn onto the floor. Secondly, using the printouts, each station profile is cut out from mdf and placed on its station axis. So, the same volume of the deck is created for furniture making. Mdf sheets are fixed to the floor with the support of two horizontal wooden elements on both sides. Other supportive elements are to connect the stations to havea more rigid system. Plan layout of partititon walls are made by wooden guides screwed to the floor to define the wall lanes "Figure 5". Guides are stiffened by bracing elements. There is also one more element located into the lanes to create two $2 \mathrm{~cm}$. thickness channels to place the mdf sheets in. Finally, partition walls construction is completed together with the posts in their cavities. 
Consequently, all volumes are built. On a wall touching to the hull perpendicularly, the profile printout here is taped on the wall as an easier way than cutting mdf sheets. Corners are marked with nails and ropes from one nail to the other at the following station are tied to recognize the shape. All detail drawings of the project are taped on walls as well. Since the furniture needs a structure behind, it is made by a wooden framingof which the elements are approximately $4 \times 4 \mathrm{~cm}$. In section and placed with $40 \mathrm{~cm}$ distances "Figure 6". Framing, a berth structure for instance, is cladded with veenered marine plywood panels to shape its vertical and horizontal surfaces but the apparent borders are made with solid wood barsor jambs [7]. The space in this structure is used for storage purposes, thus it should be reachable simply by opening a cover.

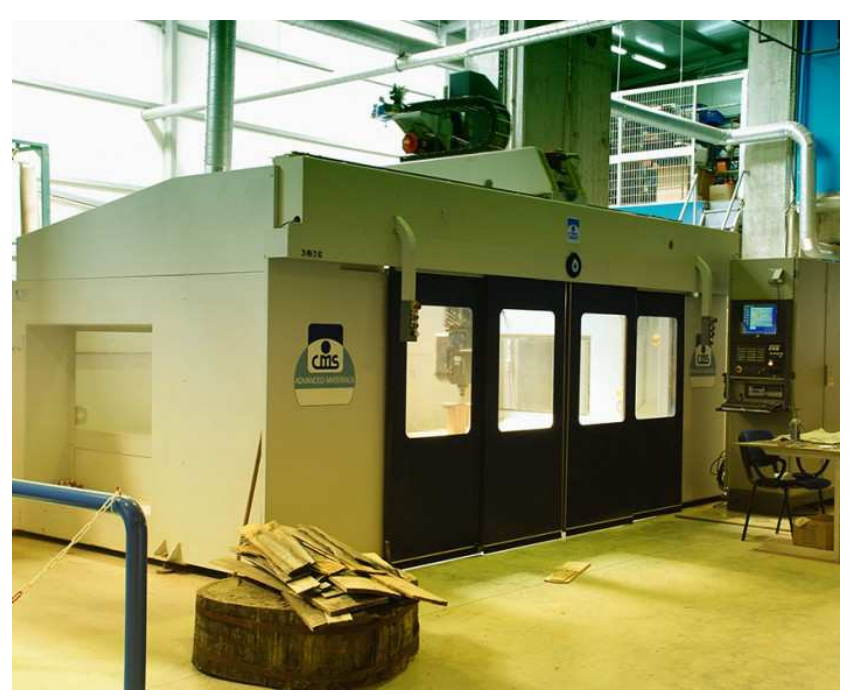

Figure 10. CNC machine is included in furniture production line.

Furnitures in a cabinshould have round corners likethe bed side stand in the given example below "Figure 7". According to the project, wall surfaces of this cabin are divided into subareas byjambs to mount thepanels in. The small gap between the cabinet and floor signifiesthat the craftsmen considered the thickness ofcarpet on the floor. Front panel of the cupboard in the figure is a long cover, therefore, four stainless steel hinges are used to prevent from bending. Similarly, sliders of a large sized drawer may not work properly, for this reason the thickness of material istested in making process [8]. Every seating unit of a boat has a storage area underneath. Its bench is panelled and each one has a hole at the mid. Cabinets in the galley are usually consisted of modules which are bolted to the wall and to each other. For the safety of navigation, each shelf has a bar in the front as a barrier and appliances such as owen, dishwasher, icemaker an freezer, all are fixed in the cabinets [9]. If the cabinet edge is round, it needs a thick wall, so, it is made with two panels and wooden posts in the cavity "Figure 8". On the other hand, round edges do not have to be this much thick and heavy always. The edge may be produced with many layers of wood veneer laminated one onto each other by gluing and pressing. This sort of craftsmenship is not common in on-site and computerized methods. Ropes as guides in the mock-up method, help to see the inclined surface of ceiling so as to checkwhether there is a conflict between the elements and existing volume. Furniture company visit the boatyard regularly from the begining to the end of construction to make a check of what is changed. This aims tokeep themselves updated. In fact, if something is changed, which happens in many cases, on time information flow is the responsibility of boatyard and they do it. But, by mistake, if something is not transmitted, it may cause a big problem whichnobody is willing to face with. Furniture company is comparably obliged to be flexible in mock-up method. Once all furnitures are finished, each piece is coded and listed, all are demounted for varnishing and polishing and then gently packedwith stretch films to be transferred to the boatyard [10]. Mounting does not take a long time and few conflicts occur than the on-site method, certainly, mockup is more advanced and organized.

\subsection{Computerized Method}

A large-scale furniture factory, works with the computerized method, has an automation system with machines and manufacturing units for the bulk production "Figure 9". Many employees, approximately 50\% in facility, $40 \%$ in mounting and $10 \%$ in design team, work in a considerably big enclosed area where the production line is settled in a different part than thedesignand administration offices. Labour division is clearly defined andthe scheduling is essential in order to finish the job at its planned date without having an overtime work [11]. This sort of production process needs a key persontosupervise theactivities such as monitoring materials, checkingthe stock, planning the machine activities and overseeing the programming. The supervisor also verifies the samples whether they fit to the quality standards, and documentsthe activities on reports. Production line is separated into two groups as furniture production and furniture finishing. A CNC machine, a sanding cabin and a vacumm press as complex machines besides the hand tools are most probably included in the first one "Figure 10". Thus, veneering or coating the plywood sheets can be made in the factory before or after the cutting. Not the wood works only, but the metal works like grinding and chrome applications may also be promised. Drying cabin, lacquer unit, polishing unit, sensitive sanding unit and many more for the best finishing are the equipments of second group. In short, machine park of the factory should have almost all needed equipments to be away from outsourcing which may cause a loss in quality and a delay in time. Such a big body works with computerized method which takes a start with the detail drawings. At the begining, design office is given the engineering project set, space layout of decks and some perspective views showing the conceptual design of interiors. Boat construction follows the project and no revision is considered unless there is a very important problem. Contract is signed, technical regulations are agreed on andtime management is made. Using the existing layout, the team 
draws all cabin plans, ceiling plans, sections, elevations as dimensioned and rendered drawings, and the $3 \mathrm{~d}$ model to get the render scenes of each cabin. Materials are indicated in the drawings. The whole set is sent to concept design office for the approval.

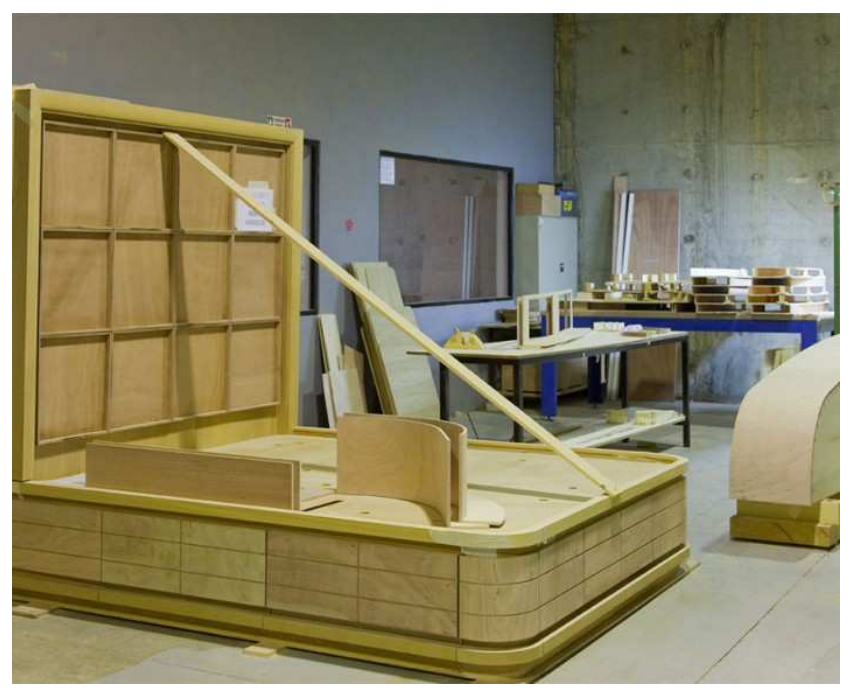

Figure 11. Furnitures are assembled in the factory.

Upon the approval, sure, the revisions are madeif demanded, then technical drawings of the furnitures are made. Every piece of a furniture, front panel, backing, sides and drawers of a bed side cabinet for instance, is drawn in $2 \mathrm{~d}$ at this phase and in $3 \mathrm{~d}$ means a blow-up drawing of each. All furnitures and pieces are coded, materials are listed and amounts are calculated in this huge drawings set. It is for the production, so, checked by the supervizor first and the production process is planned according to the best output and maximum efficiency of time and labour. No doubt that irregularities and errorsmay occur, which might be taken into account in the plan to a certain extend. Production is mainly inspected by the quality control responsible and a camera recording as well. The whole process is documented daily. Design office corrects any drawing related problem while working on the next project. Most of the pieces are cut by CNC machine using the drawings as an input, some are by the craftsmen. Forming, veneering, polishingand other operations are human controlledbut computer conducted. Air pressure in the sanding cabin and temperature in the vacuum press are measured and set by the computers, correspondingly, humidity and dustdetection and removal in the drying cabin, all calibrations, surface smoothness and painting too. Factory should have a centralized dust free air conditioning system. Galley cabinetmodules, coffee tables and berths are assembled in the factory "Figure 11". Allare then coded andto protectfrom adamage in transportation, a spray is applied, which is peeled away before mounting in the boatyard. Finally, furnitures are packed within cardboards to be transferred "Figure 12". Any problem is not expected in mounting, since the boat building and furniture making are based on thesame project. Technical issues like the pipe sizes of plumbing system or the cabling system of electricity supply is changedvery rarely, but the interior design decisions, such as color and textureof wood veneers or textiles might be changed. An information networkamong the boatyard, furniture company, concept office and investoris established. Documentation is critical in this case, minutes meeting are signed by all sides. Computerized method seems to be a high level of furniture making aims to have zero error, promises the best result and on time delivery of work. Therefore, it is the right solution for mega yachts, from 50 meters long to 80 , requires a certain amount of job capability and a boutique production. Yet, the method is a machine work, hand crafting skills and artisan work is widely excluded.

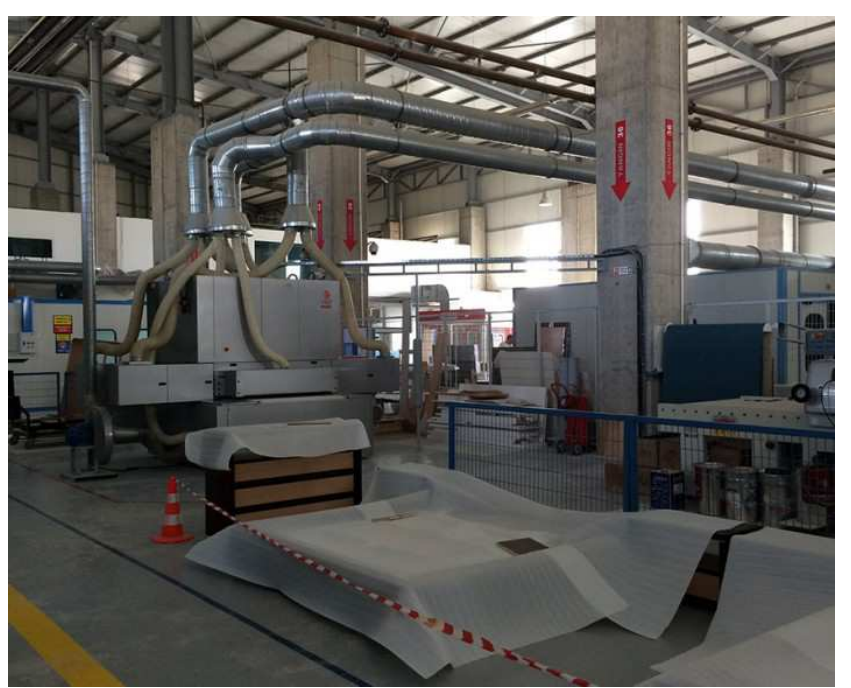

Figure 12. Furnitures are ready for packing

\section{Evaluation}

Four variables are determined to evaluate the furniture making methods: a. boat size and purpose of use, b. equipment and organizational capacity of furniture company, c. making time, andd. tolerance for decision changes. Custom tailored boats or pleasure yachts category signifies the lenght range from about 30 meters to 80 which may be grouped into three sub-categoriesstarting from 30 to 40 , then 40 to 50 and 50 to 80 . There are exceptions of course, but the first group's user orders the boat usually for the private use, second for the both private and chartering and the third's priority is to charter, means this is an investment. Related to the variable a: size and purpose, on-site method isthe right option for the first categorization of size, mock-up for the second and computerized for the third. This is also associated with the variable b: equipment and organizational capacity of furniture company. Furnitures of 50 to 80 meters long boatscan be committed by a big company with a design office and a machine park using computerized method. Companies using mock-up method may not have a CNC machine or the needed equipment for metal works, so these are outsourced, but have an enclosed area for the mock-up of a 40 meters long boat. A small team of craftsmen on the other hand, is less equipped, roles are defined as master, assistants 
and apprentices, thus, is able to build the furnitures of first category boats using on-site method. Undoubtedly, the variable c: making time in on-site method, is defined at the begining and the work is planned, however, because it is open to decision changes, so the time extends in most of the cases. Charts are prepared in the company using mock-up to obey the promised time and it is followed, so the delay may be the result of a break in information flow and a problem in outsourcing. Any delay in computerized method is not expected indeed, but the other parties, such as boatyard, concept office and investor may cause the work delayed which is subject to pay the bill. By considering the variable d: tolerance for decision changes, naturally, the computerized method has almost no tolerance for a change, only some small ones before the production started. Mock-up is able to tolerate a change during the making process to a certain extent like, if a new pipeline is added and changes the dimensions of a stepped furniture, a new one can be made by the company. On-site is the most flexible one among others, even the furniture sizes may be changed by the user and tolerated by the company. But it should be mentioned that since the boats are mostly private boats, user may change some decisions during the making process, which isthe nature of this type of work and it is usually compensated by both sides. As a conclusion, three different methods of furniture making demonstrate three different work scales, but not the quality of end product.

\section{Acknowledgements}

Emre Ergul would like to give his special thanks to boatyards and furniture companies, in an alphabetical order: Mastori Yachts, Roda, Sultan Marine and Ulutas for their kind hospitality during the visits and generosity of permitting the publication of photographs which made this article realizable. This study might not be possible without their valuable contribution.

\section{References}

[1] E. Emre, "Report: Observations and Interviews in Roda boatyard" (prepared for YD 508 course of Izmir University of Economics in 2016), unpublished.

[2] S. Peter H., "Planking and Fastening", Wooden Boat Publications, ISBN-13: 978-0937822418, 1996.

[3] E. Emre, "Report: Observations and Interviews in Mastori Yachts" (prepared for YD 508 course of Izmir University of Economics in 2009), unpublished.

[4] B. Fred P., "Boat Joinery and Cabinet Making Simplified", first edition, International Marine - Ragged Mountain Press, ISBN-13: 978-0070053076, 1993.

[5] E. Emre, "Report: Observations and Interviews in Viking Marin" (prepared for YD 508 course of Izmir University of Economics in 2008), unpublished.

[6] E. Emre, "Report: Observations and Interviews in Sultan Marine" (prepared for YD 508 course of Izmir University of Economics in 2011), unpublished.

[7] N. Michael, "Boat Interior Construction", second edition, Sheridan House, ISBN-13: 978-1574091533, 2009.

[8] R. Andy, "The Complete Illustrated guide to Furniture \& Cabinet Construction", The Taunton Press, ISBN-13: 978-156158-402-4, 2001.

[9] P. Brown, "Carpentry and Joinery", third edition, Butterworth Heinemann, 2001.

[10] S. Peter H., "Painting and Varnishing", Wooden Boat Publications, ISBN-13: 978-0937822333, 1995.

[11] E. Emre, "Report: Observations and Interviews in Ulutas company" (prepared for YD 508 course of Izmir University of Economics in 2012), unpublished. 